Supplement of Geosci. Model Dev., 13, 4253-4270, 2020

https://doi.org/10.5194/gmd-13-4253-2020-supplement

(C) Author(s) 2020. This work is distributed under

the Creative Commons Attribution 4.0 License.

(c) (1)

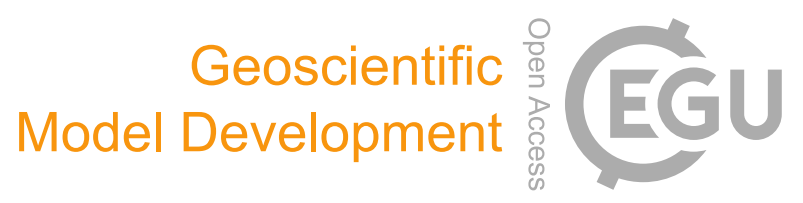

Supplement of

\title{
ML-SWAN-v1: a hybrid machine learning framework for the concentra- tion prediction and discovery of transport pathways of surface water nu- trients
}

Benya Wang et al.

Correspondence to: Carolyn Oldham (carolyn.oldham@uwa.edu.au)

The copyright of individual parts of the supplement might differ from the CC BY 4.0 License. 


\section{Supplementary results}

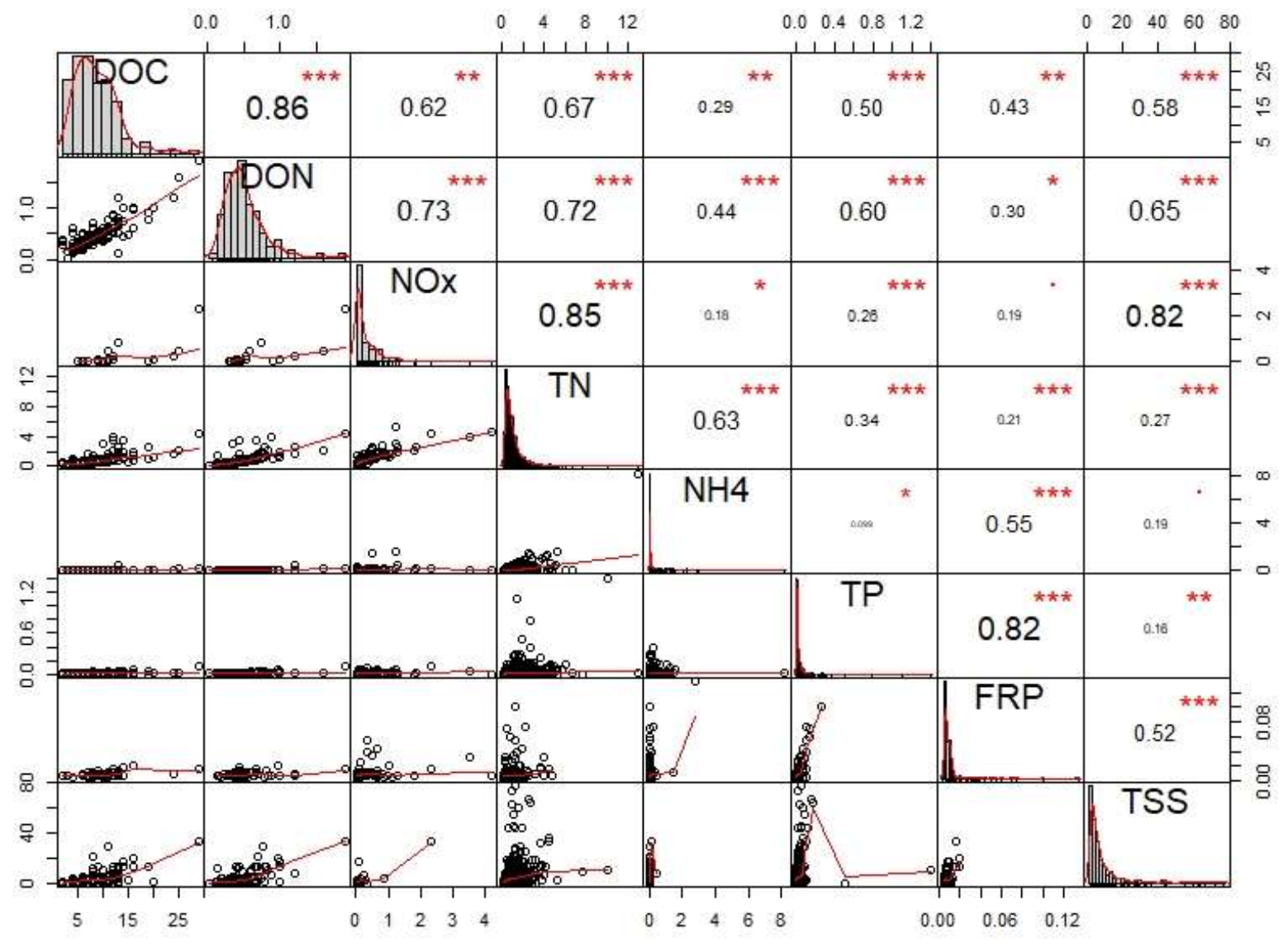

Figure S.1 Correlation between different nutrients in Murray River. 
a)
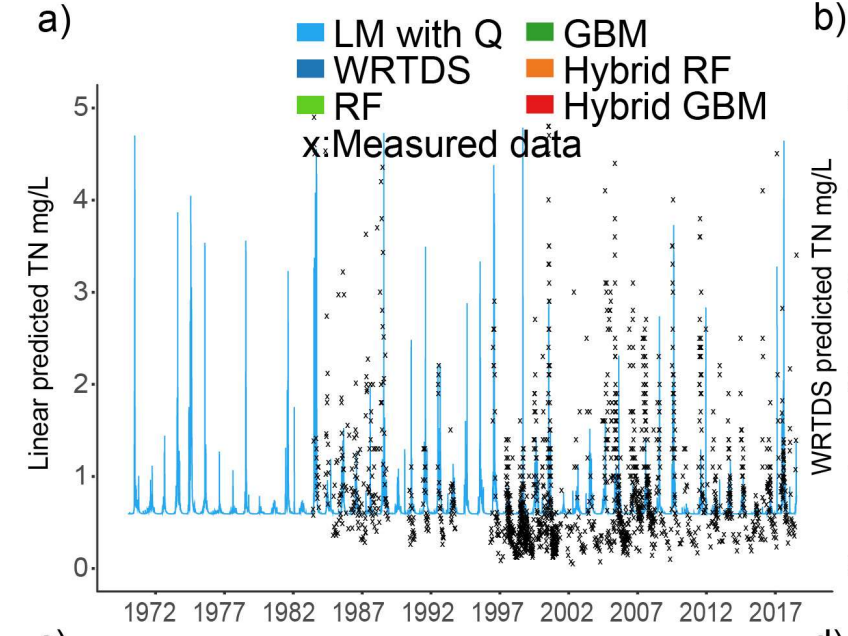

c)

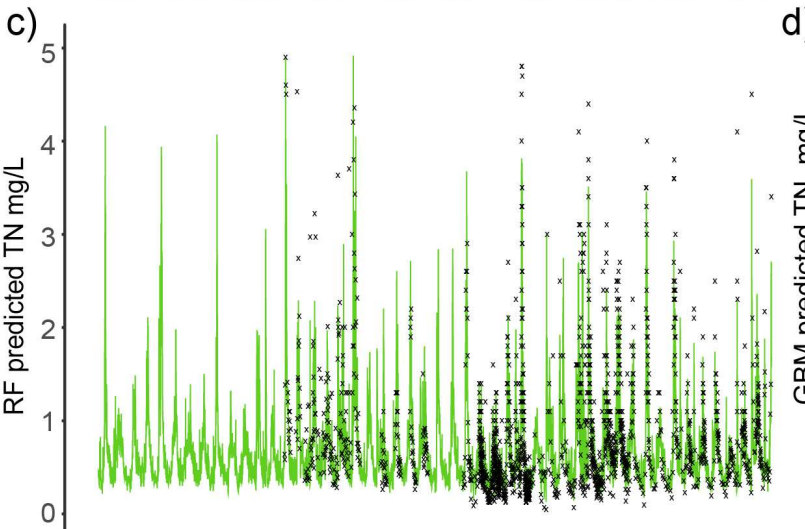

1972197719821987199219972002200720122017

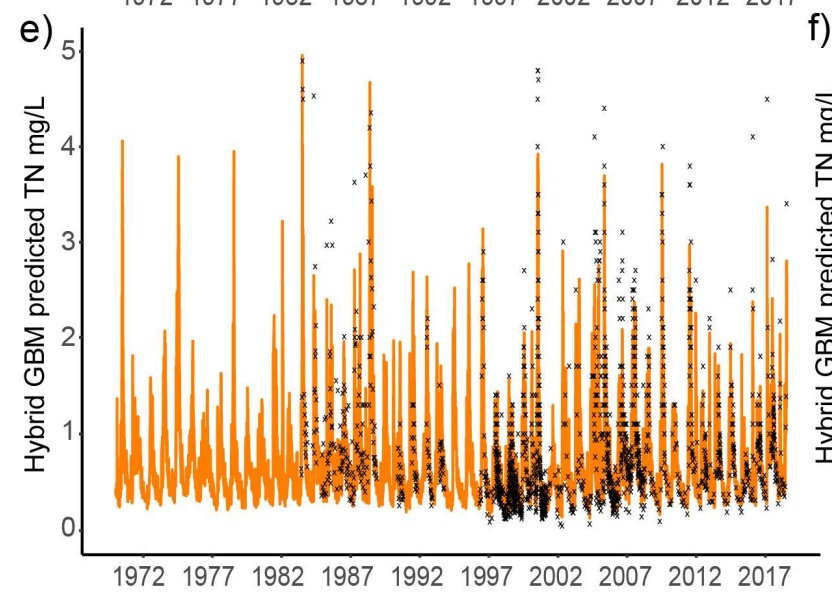

b)

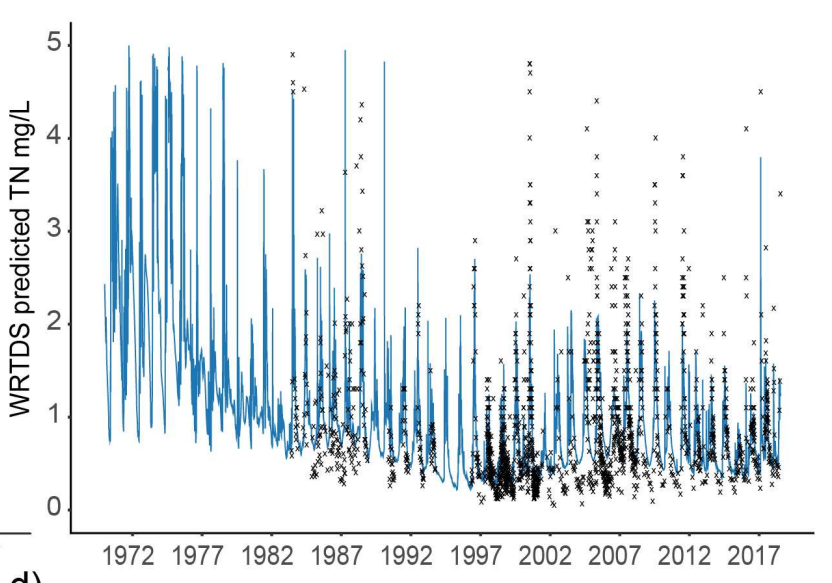

d) 5

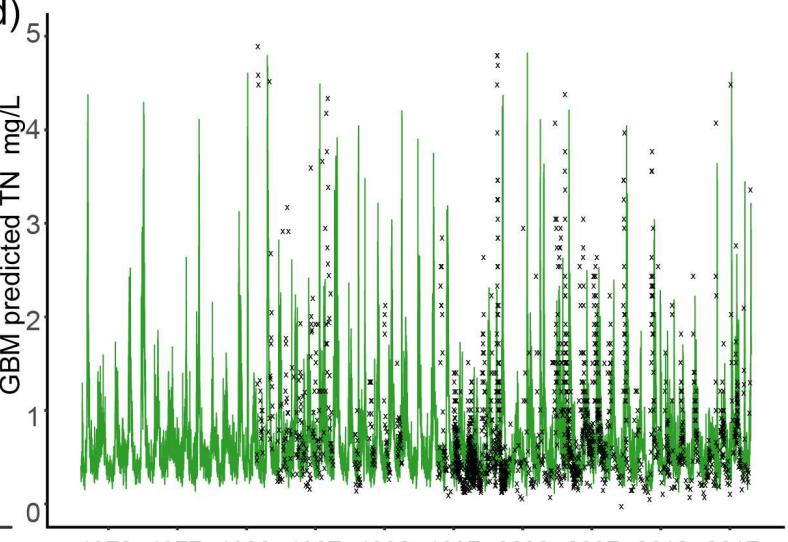

1972197719821987199219972002200720122017

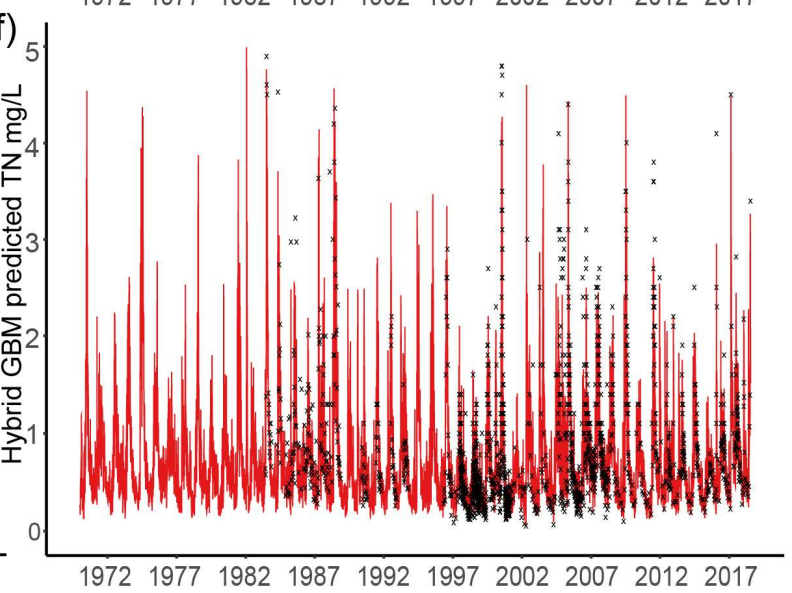

Figure S.2 Daily TN generated by the six models, for Murray River. 

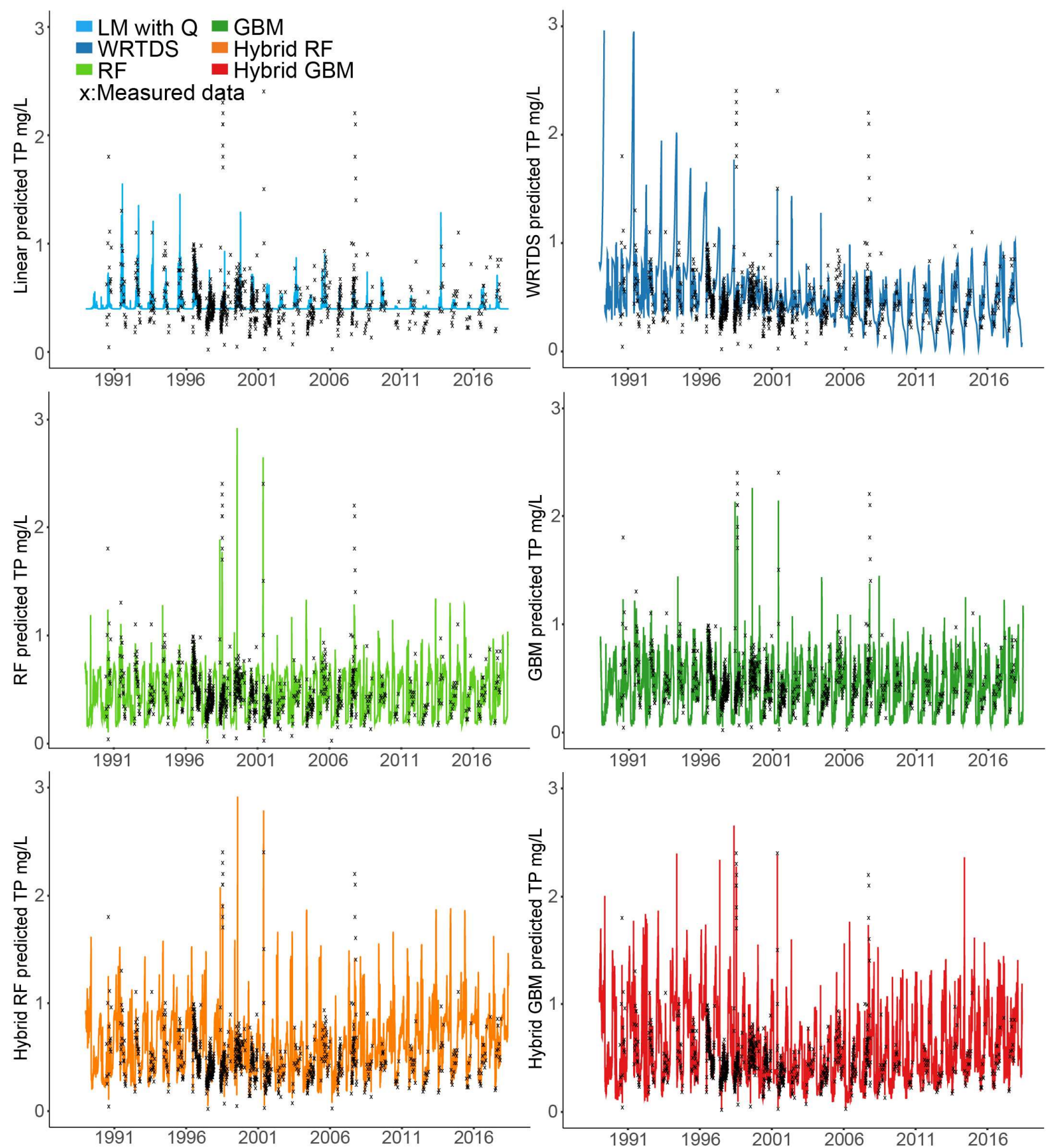

Figure S.3 Daily TP generated by the six models, for Ellen Brook. 

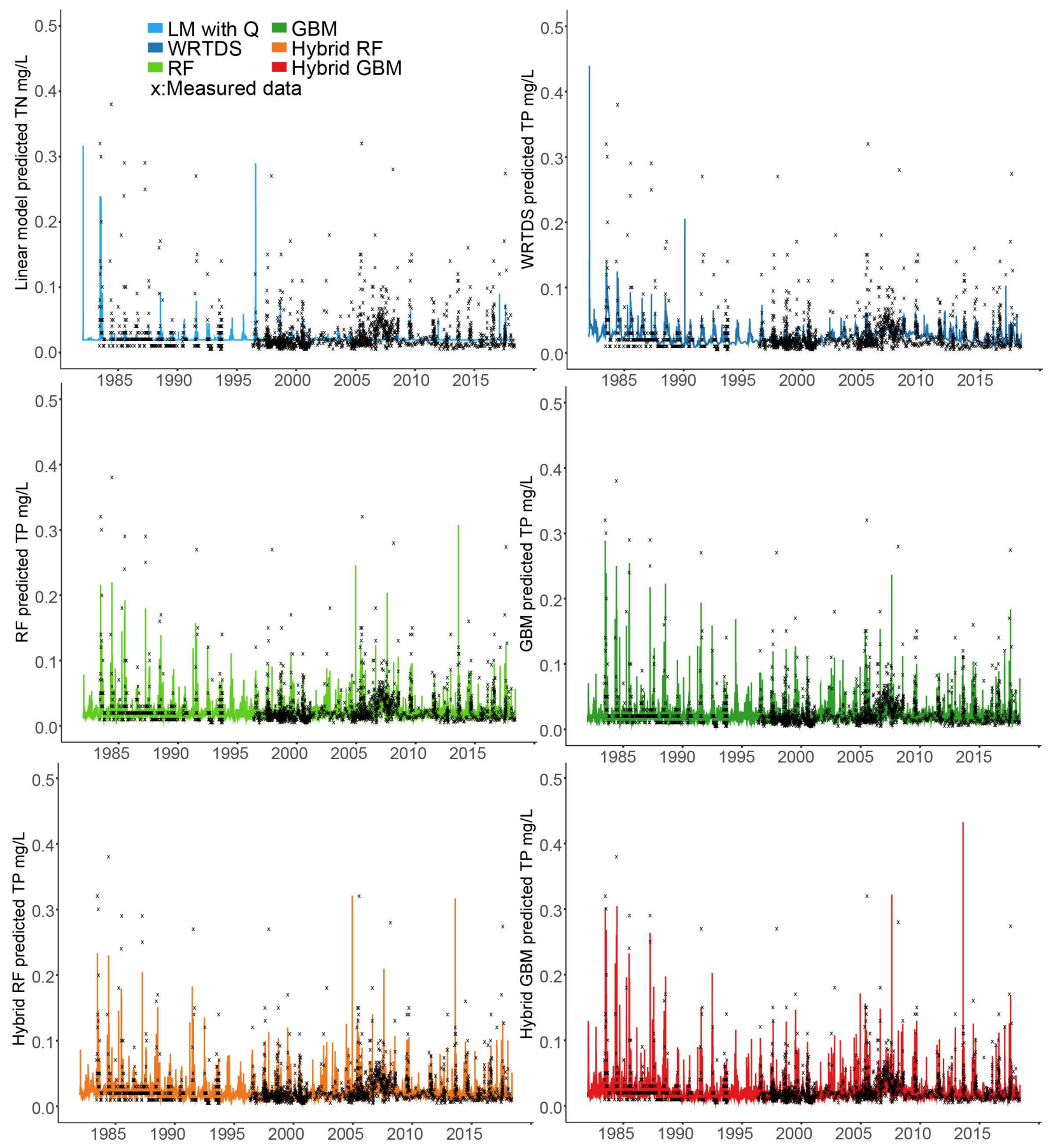

Figure S.4 Daily TP generated by the six models, for Murray River. 


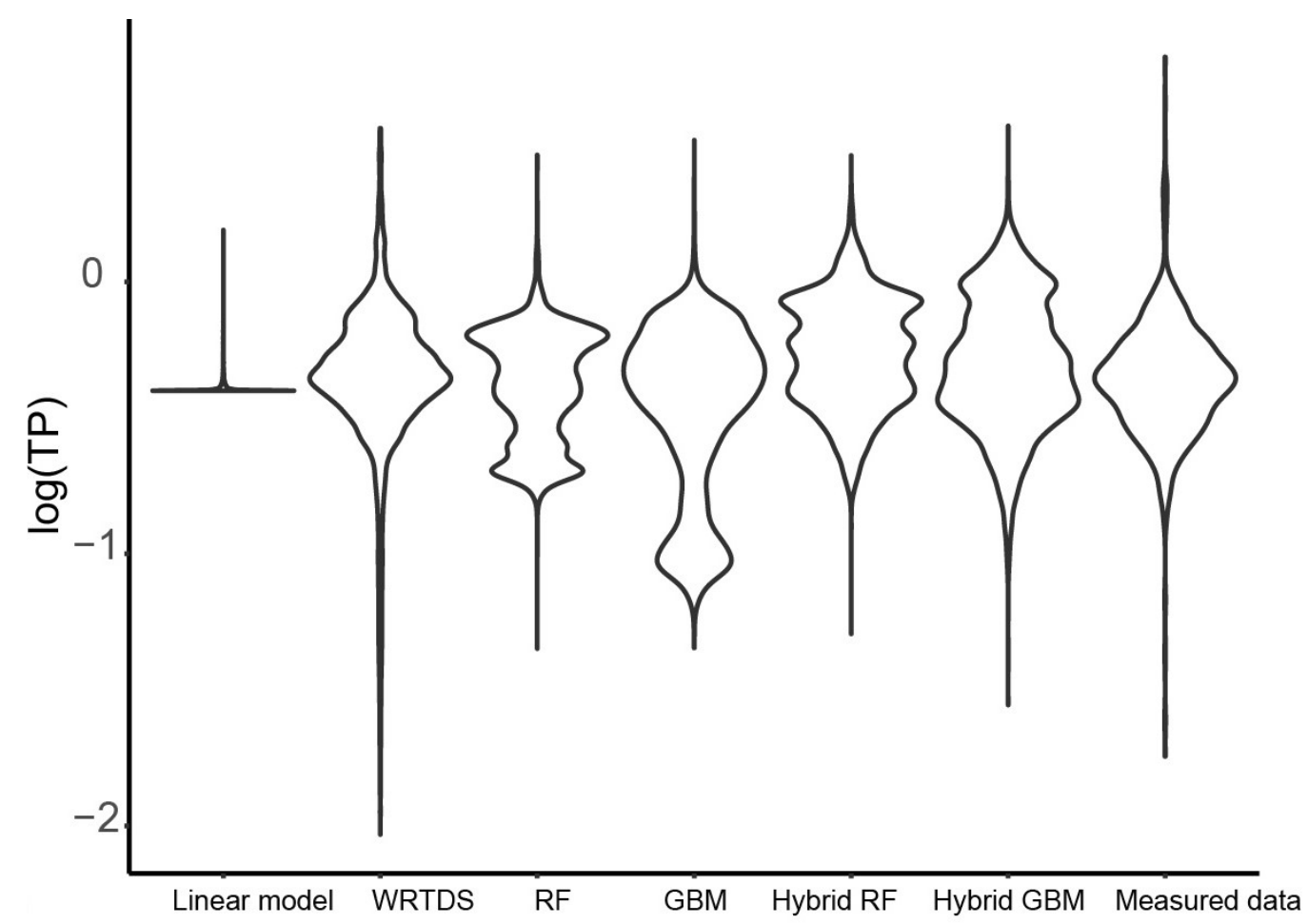

Figure S.5 The distribution of the daily TP generated by the six models, and of the measured TP data in Ellen Brook.

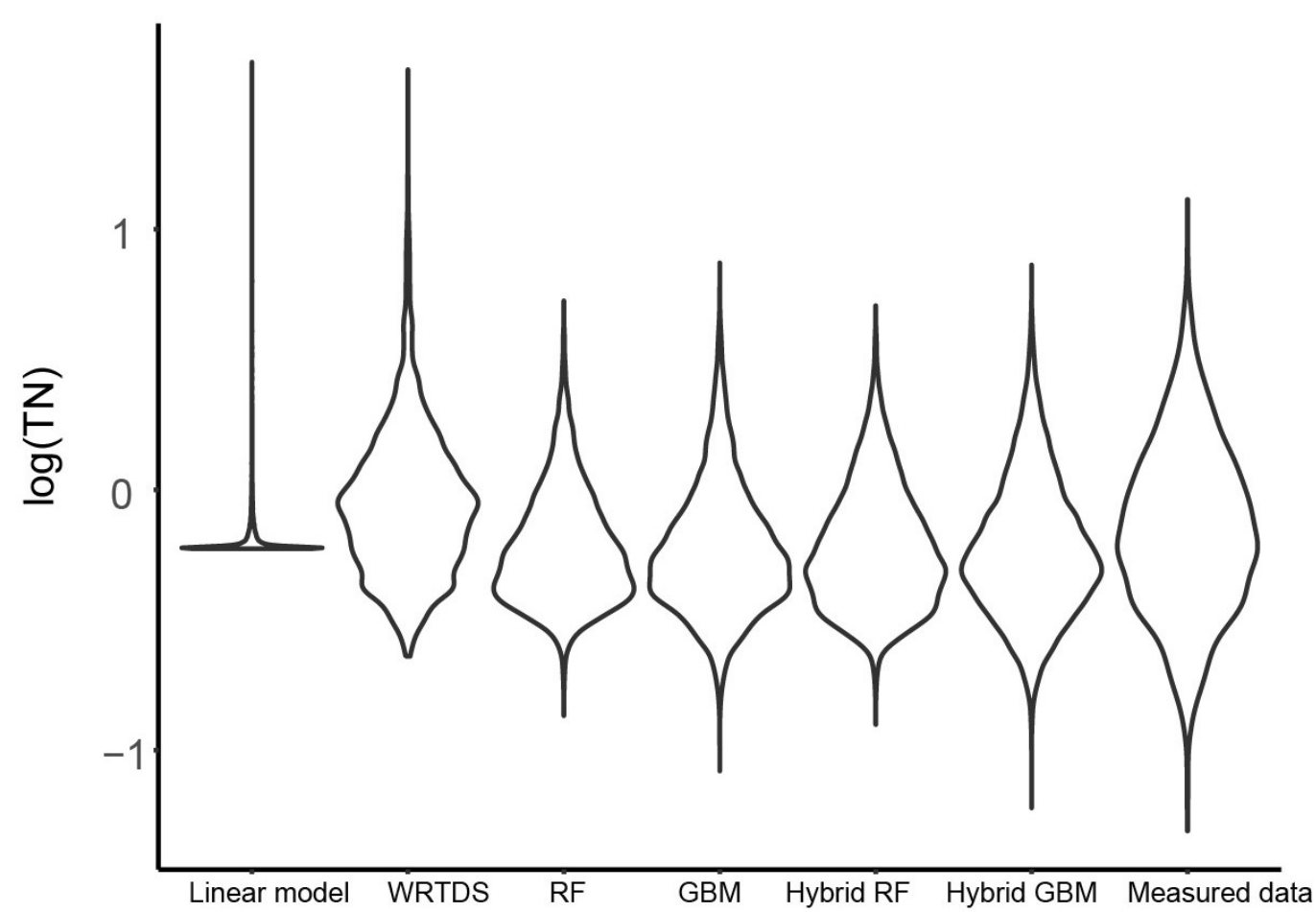

Figure S.6 The distribution of the daily TN generated by the six models, and of the measured TN data in Murray River. 


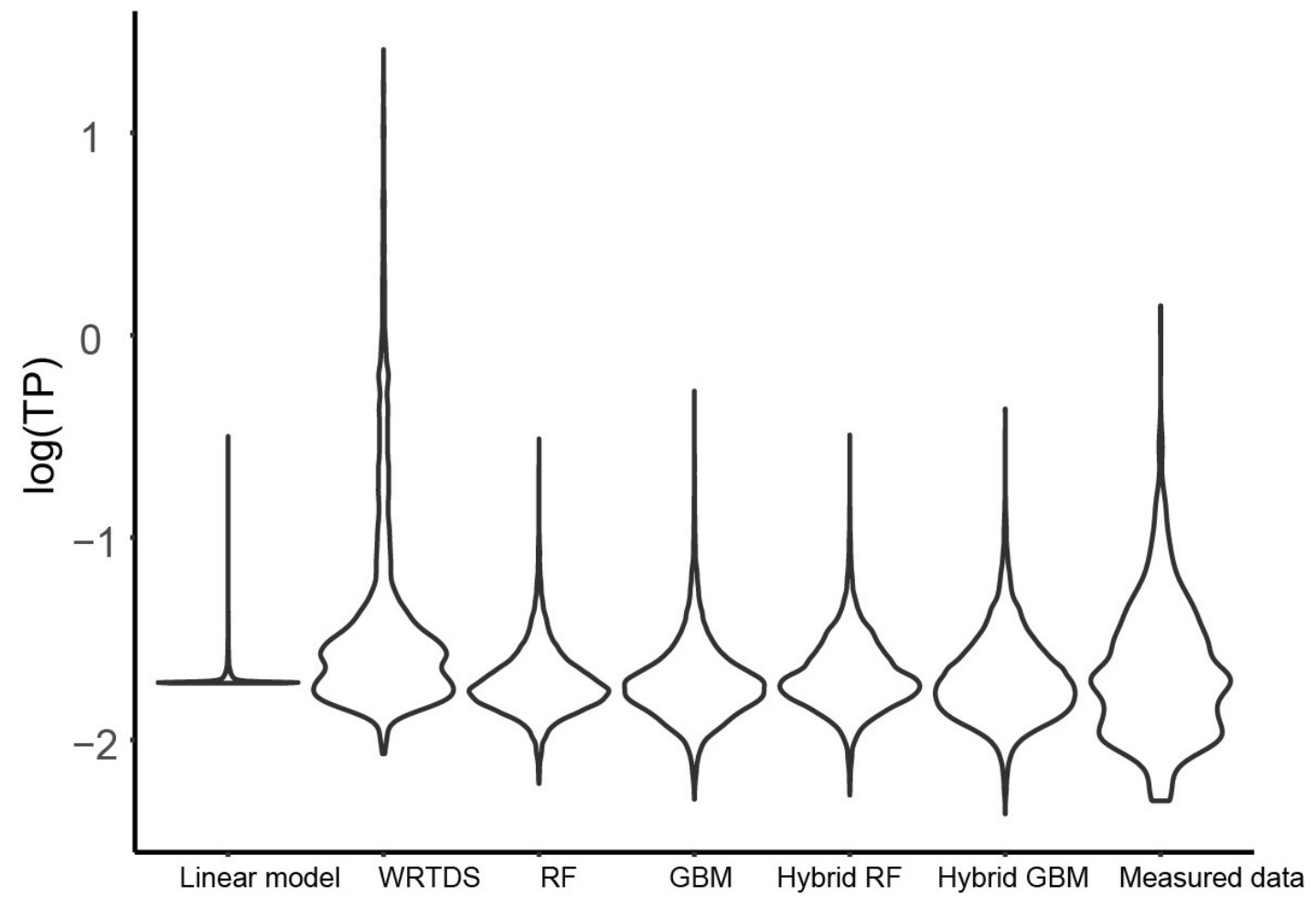

19

Figure S.7 The distribution of the daily TP generated by the six models, and of the measured TP. 21

22

23

24 